\title{
Comparison of ABTS, DPPH, Phosphomolybdenum Assays for Estimating Antioxidant Activity and Phenolic Compounds in Five Different Plant Extracts
}

\author{
Arabela UNTEA ${ }^{1}$, Alexandra LUPU ${ }^{2 *}$, Mihaela SARACILA ${ }^{3}$, Tatiana PANAITE ${ }^{4}$ \\ National Institute of Research-Development for Biology and Animal Nutrition - IBNA \\ Balotesti,Romania. \\ *Corresponding author, e-mail: alexandra.fustei@yahoo.com
}

Bulletin UASVM Animal Science and Biotechnologies 75(2)/ 2018

Print ISSN 1843-5262; Electronic ISSN 1843-536X

DOI:10.15835/buasvmcn-asb: 2018.0009

\begin{abstract}
Many plants and their constituents (carotenoids, flavonoids and other phenolic compounds), action to inhibit the free radical by the use of antioxidant activity, helping to a better efficiency of nutrients utilization. The purpose of this study was to investigate the antioxidant activity and phenolic content of five different plants, known for their antioxidant potential. Total phenols were determined by FolinCiocalteumethod, with few modifications. The antioxidant capacity was evaluated by DPPH, ABTS radical-scavenging activity and phosphomolybdenum method. The results showed that the highest antioxidant activity was obtained for walnut leaves in terms of ABTS evaluation and for bilberry leaves by DPPH and phosphomolybdenum methods. In the present study, peppermint, walnut and bilberry leaves proved to have an important antioxidant activity and also a total phenolic content.
\end{abstract}

Keywords: ABTS, DPPH, phosphomolybdenum, polyphenols, plants

\section{INTRODUCTION}

In the last decades, it has been intensively studied natural alternatives to synthetic antioxidants and the effects of antioxidative substances obtained from natural sources. Antioxidants can be synthesized in vivo or taken as dietary antioxidants, but it is known that plants are a good source of antioxidants, Kasote et al., (2015). Many active components of herbs and spices can prevent lipid peroxidation having action against free radicals or through activation of antioxidant enzymes, helping to a better efficiency of nutrients utilization, Frankič et al., (2009).

The antioxidant potential of plants has been found to be a promising method of countering the undesirable effects of oxidative stress. The most important naturally occurring plant substances showing antioxidant activity are phenolic substances (carotenoids, flavonoids and other phenolic compounds, phenolic acids, hydrolysable tannins) (Balasundram et al., 2006). In this study, we considered five plants rich in phenolic compounds: marigold, walnut leaves, peppermint, bilberry leaves and sesame seeds. Bilberry (Vaccinium myrtillus L.) leaf and fruit contain a variety of antioxidant that prevent free radicals from causing oxidative damage in cells. These benefits take place thanks to presence of catechin tannins, plant chemicals that are both astringent and anti-inflammatory, acording to Riihinen et al., (2008). For marigold (Calendula officinalis) it has been reported to contain a variety of phytochemicals, including carotenoids, terpenoids, flavonoids and other constituents, showing some important biological activities like wound healing, immuno-stimulant, spasmogenic and spasmolytic, hepatoprotective, anti-bacterial and anti-fungal, antioxidant, Jan et al., (2017). Peppermint 
(Mentha longifolia) is an herb with a wide range of pharmacological properties such as antimicrobial, gastrointestinal, and nervous system effects and used for treatment of various diseases such as headaches and digestive disorders, Mikaili et al., (2013). The walnut (Juglans Regia) leaves have tannins, phenolic compounds and other healing compounds. Walnuts are good source of flavonoids, sterols, pectic substances, phenolic acids and related polyphenols. Leaves have been used mostly in traditional medicines as antimicrobial, antihelmintic, astringent, keratolytic, antidiarrhoeal, hypoglycaemic, depurative, tonic, carminative (Taha and Al-wadaan, 2011). Sesame (Sesamum indicum L.) seeds are rich in oil, protein, dietary fiber, and micronutrients such as minerals, lignans, tocopherol, and phytosterol.

Available data indicate that natural plant products have beneficial effects on human and animal health, notably in relation to their antioxidant activity, Lee et al., (2016). For this purpose several methods were developed for measuring the total antioxidant capacity of plants, like total antioxidant capacity (TAC), free radical scavenging of DPPH radical, oxygen radical absorbance capacity (ORAC), free radical scavenging of ABTS radical, phosphomolibdenum method, Altemimi et al., (2017).

The objective of this study was to assess the antioxidant activity and phenolic content of some plants, known for their potential of countering the undesirable effects of oxidative stress by four different analytical methods.

\section{MATERIALS AND METHODS}

\section{Plant material}

All medicinal plants used were obtained from local pharmacies, dried, grounded and packed. The choice of the plants investigated was based on their use in the traditional medicine (bilberry leaves, walnut leaves, mentha leaves, sesame seeds, marigold flowers).

\section{Plant extracts}

The methanol extract was obtained by extracting $1 \mathrm{~g}$ of dried plant powder in $10 \mathrm{~mL}$ methanol and kept on a rotary shaker for $24 \mathrm{~h}$, in the dark. The extract was centrifuged at $1500 \mathrm{~g}$ for $10 \mathrm{~min}$ and the supernatant was considered for analysis.

\section{Content of Total Polyphenols}

The total phenol content of all plants extracts was measured spectrophotometrically according to the Folin-Ciocalteu's method, as described by (Astill et al., 2001) with slight modifications. Briefly, the extract samples $(0.5 \mathrm{~mL}$ of different dilutions) were mixed with $0.5 \mathrm{~mL}$ FolinCiocalteu reagent, $7 \mathrm{~mL}$ water and was homogenized. The solution was kept at room temperature for $3 \mathrm{~min}$ before adding $2 \mathrm{~mL}$ of sodium carbonate solution $20 \%$. After an hour in the dark the absorbance was measured at $732 \mathrm{~nm}$ against a blank (solution with no extract added). Calibration curve of Gallic acid was used to determine total phenol compounds, and the results were reported as mg gallic acid equivalents per gram sample (mg GAE/ g).

Total Antioxidant Capacity (TAC) by phosphomolybdenum method

The total antioxidant capacity of the plant extracts was evaluated by the method of Prieto et al., (2010). An aliquot of $0.2 \mathrm{~mL}$ of the sample solution was mixed with $4 \mathrm{~mL}$ of the reagent solution (0.6 M sulfuric acid, $28 \mathrm{mM}$ sodium phosphate and $4 \mathrm{mM}$ ammonium molybdate). For the blank, $0.2 \mathrm{~mL}$ ethanol was mixed with $4 \mathrm{~mL}$ of the reagent. The absorbance of the test sample was measured at $695 \mathrm{~nm}$. The results were reported as mmol eq ascorbic acid /Kg sample.

ABTS free radical scavenging assay

The scavenging potential of plant extracts against ABTS radical was determined using the method described by Qwele et al., (2013). The radical was generated by mixing two stock solutions of $7 \mathrm{mM}$ ABTS and $2.4 \mathrm{mM}$ potassium persulphate in the same ratio and allowed to react in the dark for $12 \mathrm{~h}$ at room temperature. This solution was further diluted with ethanol to adjust its absorbance to 0.70 at $734 \mathrm{~nm}$. The diluted ABTS+ solution $(6 \mathrm{~mL})$ was reacted with $40 \mu \mathrm{L}$ of the supernatant followed by measuring the absorbance at $734 \mathrm{~nm}$ (Jasco V-530, Japan Servo Co.Ltd., Japan) using ethanol as blank. The scavenging activity of sample against ABTS radical was expressed using a standard calibration curve constructed by plotting percentage inhibition against concentration of trolox. The results were reported as mmol eq trolox/Kg sample.

DPPH free radical scavenging assay

DPPH radical-scavenging activity of the supplements was estimated by the method of Qwele et al., (2013). A volume of $2 \mathrm{~mL}$ of $0.2 \mathrm{mM}$ DPPH prepared in methanol was added to 400 $\mu \mathrm{L}$ supernatant and $1.6 \mathrm{~mL}$ distilled water. The mixture was vortexed and left to stand at room 
Table 1. Total polyphenol content and antioxidant activity of selected plants

\begin{tabular}{ccccc}
\hline & $\begin{array}{c}\text { ABTS } \\
\text { mmol eq trolox/Kg }\end{array}$ & $\begin{array}{c}\text { DPPH } \\
\text { mmol eq trolox/Kg }\end{array}$ & $\begin{array}{c}\text { TAC } \\
\text { mmol eq ascorbic } \\
\text { acid/Kg }\end{array}$ & $\begin{array}{c}\text { Total polyphenol } \\
\text { content } \\
\text { Mg GAE/g }\end{array}$ \\
\hline Marigold & 65.69 & 225.14 & 135.74 & 10.42 \\
\hline Mentha & 285.74 & 228.02 & 105.57 & 71.95 \\
\hline Sesame seeds & 31.77 & 72.51 & 28.82 & 5.61 \\
\hline Bilberry leaves & 320.94 & 255.83 & 196.22 & 52.82 \\
\hline Walnut leaves & 332.36 & 196.25 & 186.79 & 53.94 \\
\hline
\end{tabular}

Table 2. Antioxidant methods determination and polyphenols content correlation

\begin{tabular}{cccc}
\hline & ABTS & DPPH & TAC \\
\hline DPPH & 0.64 & & \\
\hline TAC & 0.75 & 0.81 & \\
\hline Total polyphenols content & 0.92 & 0.61 & 0.52 \\
\hline
\end{tabular}

temperature for $30 \mathrm{~min}$. A tube containing $2 \mathrm{~mL}$ of methanol and $2 \mathrm{~mL}$ of DPPH solution was used as control. The absorbance of the solution was measured at $517 \mathrm{~nm}$ using a spectrophotometer (Jasco V-530, Japan Servo Co.Ltd., Japan). The scavenging activity of sample against DPPH radical was expressed using a standard calibration curve constructed by plotting percentage inhibition against concentration of trolox. The results were reported as mmol eq trolox/Kg sample.

Statistical analysis

All analyses were performed in triplicate, with data expressed as mean \pm standard deviation. Pearson's correlation was used to analyze the relationships between polyphenol content and antioxidant activity measured by three different methods.

\section{RESULTS AND DISCUSSIONS}

Table 1 presents the results obtained for total polyphenol content and antioxidant capacity (determination methods used: ABTS $\left(\left\{2,2^{\prime}\right.\right.$ - azinobis(3-ethyl-benzothiazoline-6-sulphonic acid)\}), DPPH (2,2-Diphenyl-1-picrylhydrazyl, total antioxidant capacity (TAC) by phosphomolybdenum method), for the five considered plants.

The results showed that the highest antioxidant activity was obtained for walnut leaves in terms of ABTS evaluation and for bilberry leaves by DPPH and phosphomolybdenum methods. Also, important results were obtained for marigold by DPPHand phosphomolybdenum methods. Sesame seeds have shown the lowest antioxidant capacity resulted from all methods used.Results reported in scientific literature showed values of $302.7 \%$ DPPH inhibition for bilberry leaves (Martz et al., 2010) and $3.47 \mathrm{~g} / \mathrm{L}$ DPPH for mentha (Mkaddem et al., 2009). In terms of ABTS evaluation, mentha was considered to have important values 195 mg/L Mkaddem et al., 2009 and 153 mg/L Nickavar et al., 2010).

Phenolic compounds are ubiquitous constituents of plants and their major sources in human diet are vegetables, fruit and various beverages. The polyphenols evaluation presented important values for mentha, walnut and bilberry leaves. Results from our study showed a wide variation in total polyphenol content of plant species tested: from sesame seeds to walnut leaves. Vinson and Cai, (2012) found values of 69.3 $\mu \mathrm{mol}$ catechin equivalents/g total polyphenols in walnut and Vishwanath et al. (2012) reported 2.88 mg gallic acid equivalents/g total polyphenols in sesame seeds.

By correlating the antioxidant capacity to phenolic compounds with antioxidant activity, it has been found that mentha has maximum values of phenolic compounds and concurrently, intense antioxidant activity. 
Table 2 presents the correlation of methods for determining the antioxidant capacity ABTS, DPPH, TAC and the total polyphenol content.

The correlation coefficients between values obtained by three antioxidant methods evaluation were between 0.6 and 0.8 . The best correlation was between TAC and DPPH with a correlation of 0.81 . Recently, Aliyu et al., (2012), found positive correlations between the determination of total antioxidant capacity by phosphomolybdenum method and DPPH assays. A good correlation is also between TAC and ABTS of 0.75. Table 2 highlighted that theABTS radical-scavenging activity reflects the polyphenols antioxidant potential, the correlation having the higher coefficient. The results suggested that the phenolic compounds contributed significantly to the antioxidant capacity of studied plants. Similar results were also obtained by Karouet et al., (2005) who showed that the total phenolic compounds contents were highly correlated with the ABTS, $\mathrm{R}=0.94$.

Phenolic compounds are considered to be the most important antioxidants of plant materials and their antioxidant activity is based on their ability to donate hydrogen atoms to free radicals (Sulaiman et al., 2011). Some authors showed correlation between total phenolic content and antioxidant activity, measured by different methods and others found no such relationship (Sulaiman et al., 2011).The low correlations might be explained that total antioxidant activity is not due to only one contributor, the presence of non-phenolic antioxidants (vitamin C, vitamin $\mathrm{E}$ and carotenoids) having accountable antioxidant activity.

\section{CONCLUSION}

In the present study, peppermint, walnut and bilberry leaves proved to have an important antioxidant activity determined by three different methods and also a total phenolic content. To confirm the beneficial effects of studied plants, further studies are necessary to establish their in vivo activity and bioavailability.

Acknowledgements. This work was supported by funds from the Romanian Ministry of Education and Research (Project PN 18-20 0102).

\section{REFERENCES}

1. Aliyu AB, Ibrahim MA, Ibrahim H, Musa AM, Lawal AY, Oshanimi JA, Usman M, Abdulkadir IE, Oyewale
AO, Amupitan JO (2012). Free radical scavenging and total antioxidant capacity of methanol extract of Ethuliaconyzoides growing in Nigeria. Romanian Biotechnological Letters, 17: 7458-7465.

2. AltemimiA, LakhssassiN, BaharloueiAW, Dennis G, Lightfoot DA (2017). Phytochemicals: Extraction, isolation, and identification of bioactive compounds from plant extracts. Plants, 6: 42.

3. Astill C, Birch MR, Dacombe C, Humphrey PG, Martin PT (2001). Factors affecting the caffeine and polyphenol contents of black and green tea infustions. Journal of Agricultural and Food Chemistry, 49: 5340 - 5347.

4. Balasundram N, Sundram K, Samman S. (2006). Phenolic compounds in plants and agri-industrial by-products: Antioxidant activity, occurrence, and potential uses. Food chemistry, 99: 191-203.

5. Frankič T, Voljč M, Salobir J, Rezar V (2009). Use of herbs and spices and their extracts in animal nutrition. Acta Agric Slov, 94: 95-102.

6. Jan N, Riffat J (2017). Calendula officinalis -an important medicinal plant with potential biological properties. Proceedings of the Indian National Science Academy 83: 769-787.

7. Karou D, Mamoudou HD, Simpore J, Traore AS (2005). Antioxidant and antibacterial activities of polyphenols from ethnomedicinal plants of Burkina Faso. African Journal of Biotechnology, 4: 823-828.

8. Kasote DM, Katyare SS, Hegde MV, Bae H (2015). Significance of antioxidant potential of plants and its relevance to therapeutic applications. International Journal of Biological Sciences, 11: 982.

9. LeeMT, Lin WC, Yu B, LeeTT (2016). Antioxidant capacity of phytochemicals and their potential effects on oxidative status in animals. Asian-Australas J Anim Sci, 30: 299-308.

10. Martz F, Jaakola L, Julkunen-Tiitto R, Stark S (2010). Phenolic Composition and Antioxidant Capacity of Bilberry (Vaccinium myrtillus) Leaves in Northern Europe Following Foliar Development and Along Environmental Gradients. Journal of Chemical Ecology, 36: 1017-1028.

11. Mikaili P, Mojaverrostami S, Moloudizargari M, Aghajanshakeri S (2013). Pharmacological and therapeutic effects of Mentha Longifolia L. and its main constituent, menthol. Ancient science of life, 33: 131.

12. Mkaddem M, Bouajila J, Ennajar M, Lebrihi A, Mathieu F, Romdhane M (2009). Chemical composition and antimicrobial and antioxidant activities of Mentha (Longifolia L. and Viridis) essential oils. Journal of Food Science, 74: M358-M363.

13. Nickavar B, Alinaghi A, Kamalinejad M (2010). Evaluation of the antioxidant properties of five Mentha species. Iranian Journal of Pharmaceutical Research, 203209.

14. Prieto A, Basauri O, Rodil R, Usobiaga A, Fernández LA, Etxebarria N, Zuloaga O (2010). Stir-bar sorptive extraction: a view on method optimisation, novel applications, limitations and potential solutions. Journal of Chromatography A, 1217: 2642-2666. 
15. Qwele K, Hugo A, Oyedemi SO, Moyo B, Masika PJ, Muchenje V (2013). Chemical composition, fatty acid content and antioxidant potential of meat from goats supplemented with Moringa (Moringa oleifera) leaves, sunflower cake and grass hay. Meat Science, 93: 455-462.

16. RiihinenK,Jaakola L,Kärenlampi S,Hohtola A (2008). Organ-specific distribution of phenolic compounds in bilberry (Vaccinium myrtillus) and 'northblue' blueberry (Vaccinium corymbosum $\mathrm{x}$ V. angustifolium). Food Chemistry,110: 156-160.

17. Sulaiman SF, Yusoff NAM, Eldeen IM, Seow EM, Sajak AAB, Ooi KL (2011). Correlation between total phenolic and mineral contents with antioxidant activity of eight Malaysian bananas (Musa sp.). Journal of Food Composition and Analysis, 24: 1-10.

18. Taha NA, Al-wadaan MA (2011). Utility and importance of walnut, Juglans regia Linn. African Journal of Microbiology Research, 5: 5796-5805.

19. Vinson JA, Cai Y (2012). Nuts, especially walnuts, have both antioxidant quantity and efficacy and exhibit significant potential health benefits. Food \& function, 3: 134-140.

20. Vishwanath HS, Anilakumar KR, Harsha SN, Khanum F, Bawa AS (2012). In vitro antioxidant activity of Sesamum indicum seeds. Asian Journal of Pharmaceutical and Clinical Research, 5: 56-60. 